\title{
Results of the double-blind randomized controlled trial comparing laser hemorrhoidoplasty with sutured mucopexy and excisional hemorrhoidectomy
}

\author{
Tomas Poskus $^{1,2}$ (D) - Donatas Danys ${ }^{1,2}$ (D) - Gabija Makunaite ${ }^{1}$ (D) - Antanas Mainelis An $^{2,3}$ (D) Saulius Mikalauskas ${ }^{1,2}$ (D) \\ Eligijus Poskus $^{1,2}$ (D) $\cdot$ Valdemaras Jotautas $^{1,2}$ (I) $\cdot$ Audrius Dulskas $^{4}$ (D) $\cdot$ Eugenijus Jasiunas $^{2}$ (D) $\cdot$ Kestutis Strupas $^{1,2}$ (i)
}

Accepted: 12 November 2019 / Published online: 8 January 2020

(C) The Author(s) 2020

\begin{abstract}
Purpose To compare the results of laser hemorrhoidoplasty (LHP), excisional hemorrhoidectomy (EH), and sutured mucopexy (MP). Methods A randomized, parallel-group, double-blinded, single-center prospective study.

Patients Symptomatic 2nd- or 3rd-degree hemorrhoids patients.

Interventions Computer randomization sequence, patient blinding, operating surgeon blinding, and surgeon-evaluator blinding. LHP was performed using a $1470 \mathrm{~nm}$ diode laser. Up to $250 \mathrm{~J}$ of energy delivered per 1 hemorrhoid. The procedure was performed circumferentially. MP ligations were placed in the area of visible hemorrhoidal tissue. Standard EH was performed up to the level of the hemorrhoidal pedicle. Follow-up at 1 and 6 weeks and 1 year.

Outcome measures Recurrence of symptoms requiring treatment, intensity, and duration of pain after the operation, patients' quality of life, fecal incontinence, and patients' evaluation of treatment.

Results A total of 121 patients. Groups were even preoperatively. LHP took $15 \mathrm{~min}$ (SD 5.6), MP took $16 \mathrm{~min}$ (SD 5.58), and EH took $29 \mathrm{~min}$ (SD 10.3). Recurrence requiring treatment rate was 0\% after EH, 10\% after LHP, and 22\% after MP, $p=0.004$. LHP and MP were less painful than $\mathrm{EH}, p<0.001$. Patients after LHP returned to regular activity after 15 days, after MP after 22 days, and after EH after 30 days, $p<0.001$. SF-36 scores were better after EH. Symptoms of fecal incontinence improved in all the groups. Patients evaluate LHP better than EH and MP.

Limitations Single-center study.

Conclusions Laser hemorrhoidoplasty is a safe, minimally invasive option for hemorrhoids, more effective than MP and less effective than EH. Patients evaluate this technique better than the other two.
\end{abstract}

Keywords Hemorrhoids $\cdot$ Hemorrhoidectomy $\cdot$ Laser hemorrhoidoplasty $\cdot$ Intrahemorrhoidal laser $\cdot$ Sutured mucopexy $\cdot$ THD

\section{Introduction}

The research and debates on the best choice of treatment for hemorrhoids are on-going. The most effective

Tomas Poskus

toshcus@yahoo.com

1 Faculty of Medicine, Vilnius University, Vilnius, Lithuania

2 Center of Abdominal Surgery, Vilnius University Hospital Santara Clinics, Santariskiu Street, LT-08661 Vilnius, Lithuania

3 Faculty of Mathematics and Informatics, Vilnius University, Vilnius, Lithuania

4 National Cancer Institute, Vilnius, Lithuania procedure - excisional hemorrhoidectomy-causes the most pain to the patient [1]. Two recent large randomized trials compared excisional hemorrhoidectomy with stapled hemorrhoidopexy [2], and rubber band ligation with hemorrhoidal artery ligation [3]. The first trial conclusively proved that excisional hemorrhoidectomy is more effective and cheaper than stapled hemorrhoidopexy. The second trial showed rubber band ligation was shown to be as effective as Doppler-guided hemorrhoidal artery ligation after finishing the series of banding procedures. It is also significantly cheaper. However, significant and prolonged postoperative pain after excisional hemorrhoidectomy and high recurrence rate after rubber band ligation demand further improvement of treatment modalities of hemorrhoids. 
Intrahemorrhoidal laser coagulation or laser hemorrhoidoplasty (LHP) was first described in 2009 [4] and reported in larger series of patients in 2010 [5]. A few case series, including our own experience [6], as well as the experience of Weyand [7] suggested this method to be a technically simple, minimally invasive, safe, and effective procedure for symptomatic hemorrhoids.

Doppler-guided hemorrhoidal artery ligation was compared with sutured hemorrhoidopexy, or mucopexy, alone in three randomized controlled trials [8-10], with all the trials showing no benefit of the Doppler use in controlling hemorrhoidal symptoms. Sutured hemorrhoidopexy without the use of Doppler (sometimes called sutured mucopexy) could be an inexpensive, minimally invasive alternative treatment for hemorrhoids.

The aim of the present study was to compare outcomes of three different operations for hemorrhoids, i.e., LHP, excisional hemorrhoidectomy (EH), and sutured mucopexy (MP) in terms of effectiveness, safety, and quality of life (QOL) of patients.

\section{Materials and methods}

It is a randomized, parallel-group (1:1:1), double-blinded, single-center prospective study. No changes in methods of the study were allowed after commencement. Flowchart of the study is presented in Fig. 1. This study was performed in Vilnius University Hospital Santara Clinics, Vilnius, Lithuania. It is a large tertiary university hospital with a dedicated outpatient clinic. The trial was approved and registered at the Regional Bioethics Committee of Vilnius, Lithuania, on the 6th of October, 2015, registration number 158200-15792-322 (Appendix figure 1). All patients signed the informed consent form for participation in the study in addition to the consent form for the operation.

\section{Inclusion and exclusion criteria}

Patients with symptomatic 2nd- or 3rd-degree hemorrhoids, in the 1st to 3rd risk group of ASA (American Society of Anesthesiologists), who consented to participate were

Fig. 1 Flowchart of the trial

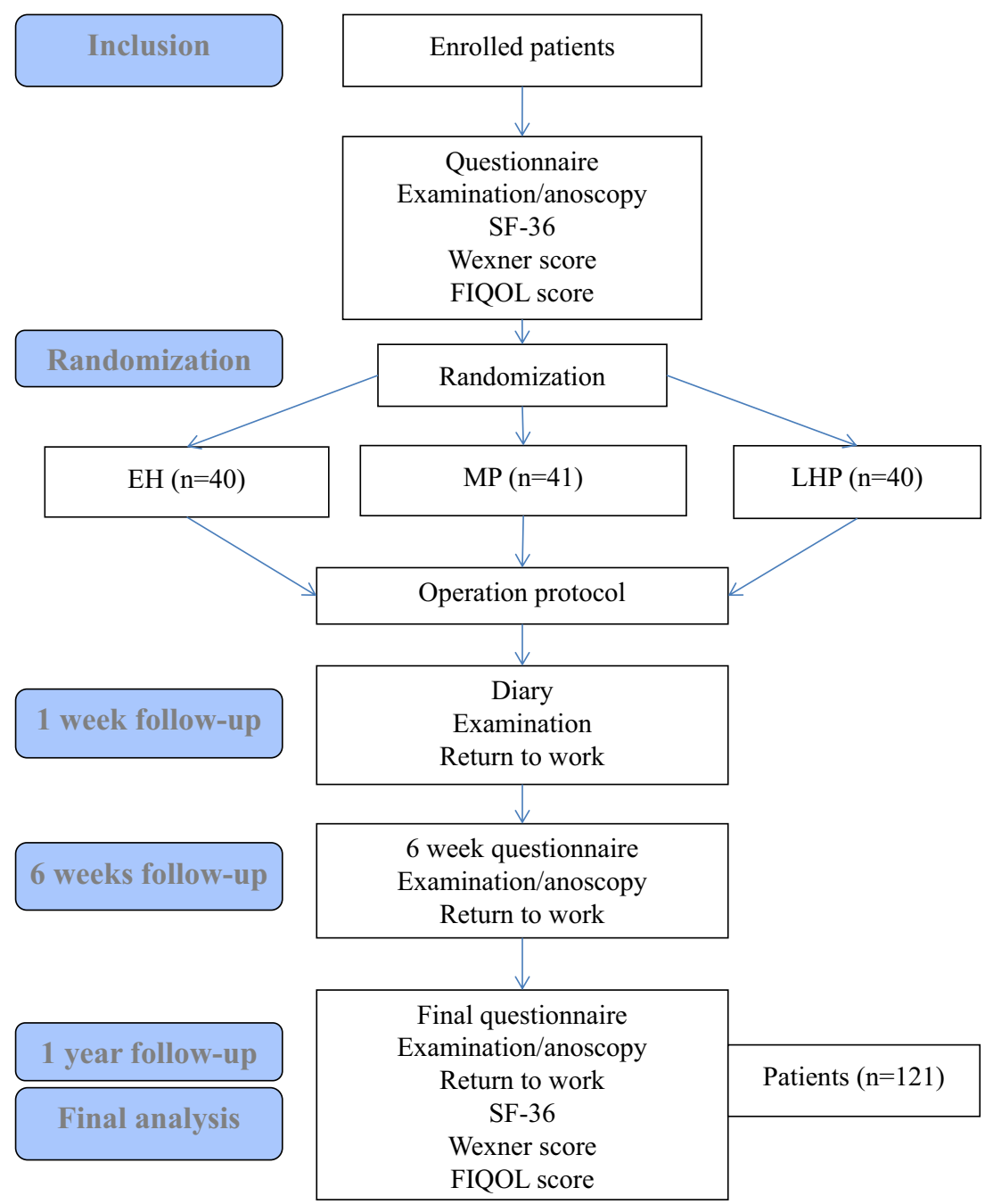


included in the study. Exclusion criteria were 1st- or 4thdegree of hemorrhoids, pregnancy, patients with other anorectal diseases (fistula, abscess, rectal carcinoma, inflammatory bowel disease, etc.), patients after previous anal operations (except rubber band ligation, which should have occurred more than 3 months before the inclusion into the trial), and 4th or higher risk group of ASA.

\section{Preoperative evaluation}

The detailed physical and anorectal examination was performed with anoscopy and rigid proctoscopy in all cases, as well as colonoscopy if indicated. All patients filled a dedicated symptom questionnaire, which included questions on the intensity and frequency of hemorrhoidal prolapse, bleeding, itching, pain, and other symptoms. Every patient completed Wexner incontinence score [11], SF-36, and fecal incontinence quality of life (FIQOL) [12] questionnaires before surgery.

\section{Randomization, blinding, and concealment}

The patients were randomized into three groups. The randomization sequence was computer-generated before the start of the trial. Every consecutive case history was assigned a randomization number (1, 2, or 3 for each treatment modality). It was written and sealed within the envelope and remained unknown neither to the patient nor to the treating physician, to avoid selection bias. In the operating room, after induction of anesthesia, operating room junior staff was asked to unseal the envelope, and the intervention was performed according to the procedure assigned. Pre- and postoperative patient management was as close to identical as we could make it in all three groups. The patient remained unaware of the procedure performed until the end of the study, 1 year after the operation. The case notes and discharge summary of the patient contained the note, saying that "the patient is included in the study of hemorrhoids, patient's number is X." This number was within the locked and coded database. The surgeon, who evaluated the result of the treatment remained blinded to the procedure performed. The patients were followed up by different surgeons (EP, VJ, and KS) than the ones performing the operation. They had access to the patient notes but not to the coded database and were not able to know which procedure had been performed in a patient. In emergency situations, unblinding of the patient and treating physicians was possible but was not required or performed in any of the patients.

\section{Duration of surgery(in minutes)}
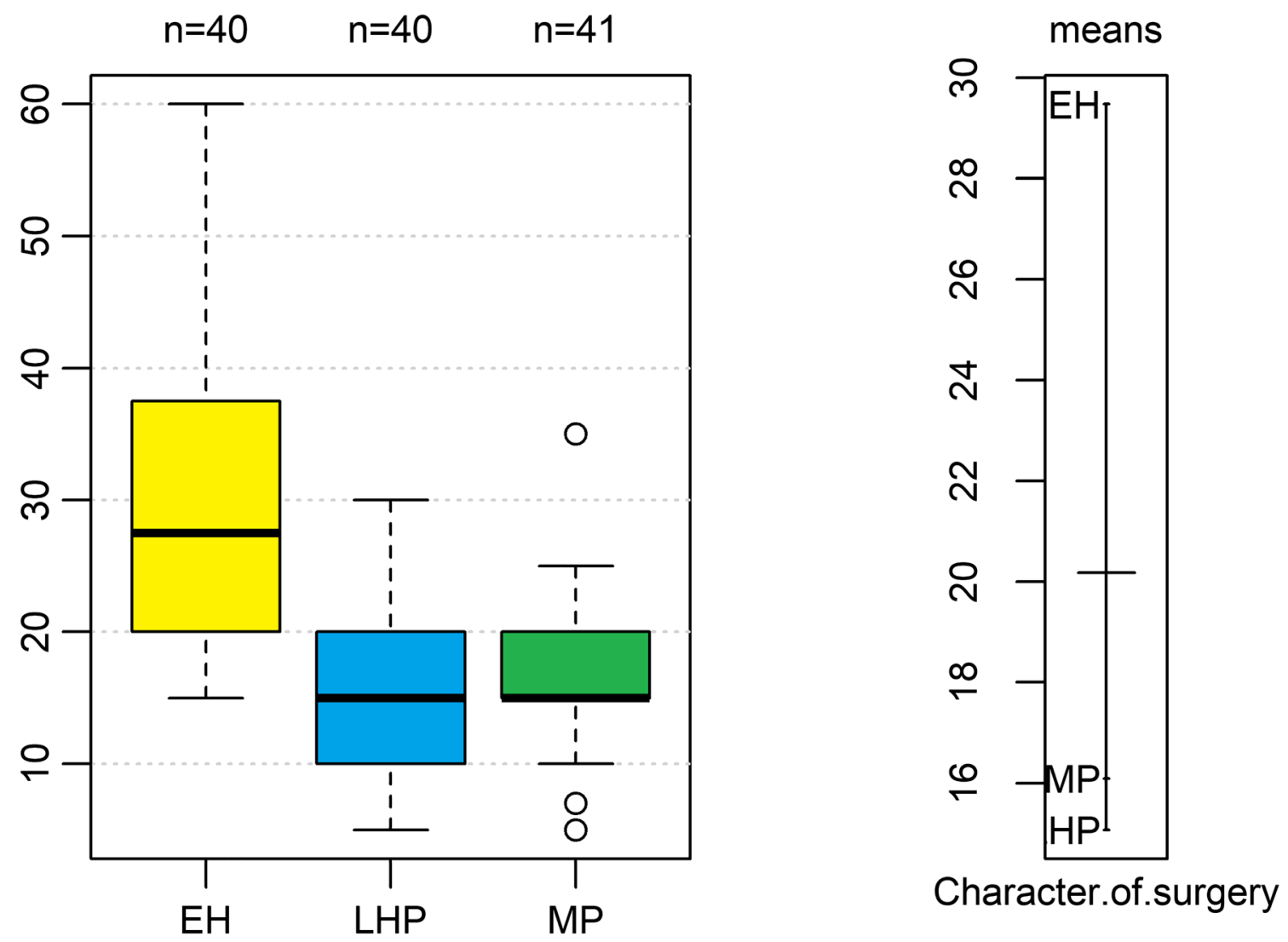

Fig. 2 Duration of surgery 


\section{Operative procedure}

Patients were started on lactulose the day before the operation, which was continued after the operation to have regular bowel movements.

Preoperative intravenous antibiotic prophylaxis was given according to the hospital protocol, which was $1 \mathrm{~g}$ of cephazolin ( $2 \mathrm{~g}$ if a patient was over $80 \mathrm{~kg}$ of weight), $240 \mathrm{mg}$ of gentamycin, and $500 \mathrm{mg}$ of metronidazole (ciprofloxacin could be used if a patient was allergic to cephalosporins).

Each surgeon performing operative procedures (TP, DD, and SM) had personal experience of at least 50 operations of each modality. A 1-h seminar was conducted between all surgeons before the start of the trial to unify the technique of operative procedures.

All patients were photographed after induction of anesthesia before the start of the procedure and immediately after the procedure.

LHP was performed using a Ceralas diode laser of $1470 \mathrm{~nm}$ wavelength (Biolitec). Disposable LHP kit (Biolitec) was used, which contains sharp-tipped laser fiber and anoscope. Perianal skin immediately aboral to hemorrhoid was penetrated using needle tip cautery (Fig. 2). Laser fiber was introduced into the opening until the level of hemorrhoidal pedicle and coagulation was activated. A total of $8 \mathrm{~W} 3$ s pulses with 1-s pulse-pauses were used to coagulate the area of hemorrhoids. A total of $4 \mathrm{~mm}$ of hemorrhoidal tissue is coagulated with one such pulse. A total of $250 \mathrm{~J}$ was the upper limit of energy delivered per 1 hemorrhoidal quadrant. Smaller hemorrhoids were treated with less energy. The procedure was repeated in the other three quadrants, thus treating all anal circumference.
MP was performed as described by Schurmann JP et al. [8]. Ligations were placed in the area of visible hemorrhoidal tissue. It was started with a single suture ligation at the level of hemorrhoidal pedicle which should incorporate the feeding vessel and continued down until above the dentate line. The continuous suture was tied, thus lifting the prolapsing hemorrhoidal tissue.

Standard EH was performed up to the level of the hemorrhoidal pedicle, with ligation or suture ligation of the pedicle and meticulous hemostasis.

\section{Follow-up}

Follow-up was performed by the different surgeons to those performing the operations (EP, VJ, and KS). Each of them had more than 25 years of experience of colorectal and hemorrhoidal surgery. The 1-h seminar was conducted, with them to unify the evaluation of the patients within the study. None of the evaluators knew which operation was performed, and they had no access to coded database of operations performed. Patient documents only mentioned that they were included in the study and study number but not which operation had been performed.

Each patient was followed up at 1 and 6 weeks and after 1 year after the operation. Perianal examination with photographic documentation was performed during all visits. Anoscopy was performed during visits at 6 weeks and 1 year.

Each patient was asked to fill in the diary every day of the first postoperative week and present it at the first visit after 1 week. Symptom questionnaires were filled in during visits at 1 and 6 weeks and 1 year. Wexner incontinence score, FIQOL, and SF-36 were filled in by the patient during the visit at 1 year.

Table 1 Demographic and preoperative clinical characteristics of the groups

\begin{tabular}{|c|c|c|c|c|c|c|c|c|}
\hline & & \multicolumn{6}{|c|}{ Operation } & \multirow[b]{3}{*}{$p$} \\
\hline & & \multicolumn{2}{|c|}{ LHP, $n=40$} & \multicolumn{2}{|c|}{$\mathrm{EH}, n=40$} & \multicolumn{2}{|c|}{ MP, $n=41$} & \\
\hline & & $N$ & $\%$ & $\mathrm{~N}$ & $\%$ & $\mathrm{~N}$ & $\%$ & \\
\hline Age & & $47=$ & & 45 & & $49=$ & & 0.420 \\
\hline Sex & $\begin{array}{l}\text { Women } \\
\text { Men }\end{array}$ & $\begin{array}{l}13 \\
27\end{array}$ & $\begin{array}{l}32.5 \\
67.5\end{array}$ & $\begin{array}{l}19 \\
21\end{array}$ & $\begin{array}{l}47.5 \\
52.5\end{array}$ & $\begin{array}{l}19 \\
22\end{array}$ & $\begin{array}{l}46.3 \\
53.7\end{array}$ & 0.349 \\
\hline Degree of hemorrhoids & $\begin{array}{l}\text { 2nd } \\
3 \text { rd }\end{array}$ & $\begin{array}{l}10 \\
30\end{array}$ & $\begin{array}{l}25.0 \\
75.0\end{array}$ & $\begin{array}{r}7 \\
33\end{array}$ & $\begin{array}{l}17.5 \\
82.5\end{array}$ & $\begin{array}{l}10 \\
31\end{array}$ & $\begin{array}{l}24.4 \\
75.6\end{array}$ & 0.669 \\
\hline No concomitant diseases & & 29 & 72.5 & 24 & 60.0 & 21 & 51.2 & 0.143 \\
\hline Bleeding & & 34 & 85.0 & 35 & 87.5 & 37 & 90.2 & 0.742 \\
\hline Prolapse & & 32 & 80.0 & 32 & 80.0 & 35 & 85.4 & 0.769 \\
\hline Itching & & 10 & 25.0 & 7 & 17.5 & 5 & 12.2 & 0.325 \\
\hline Pain & & 11 & 27.5 & 14 & 35.0 & 15 & 36.6 & 0.651 \\
\hline Fecal incontinence & & 1 & 2.5 & 0 & 0.0 & 0 & 0.0 & 0.661 \\
\hline Other symptoms & & 11 & 27.5 & 13 & 32.5 & 14 & 34.1 & 0.799 \\
\hline
\end{tabular}


Table 2 Outcomes of the study (statistically significantly best outcomes are in italics)

\begin{tabular}{|c|c|c|c|c|c|c|c|}
\hline & \multicolumn{6}{|c|}{ Operation } & \multirow[b]{3}{*}{$p$} \\
\hline & \multicolumn{2}{|c|}{ LHP, $n=40$} & \multicolumn{2}{|c|}{$\mathrm{EH}, n=40$} & \multicolumn{2}{|c|}{ MP, $n=41$} & \\
\hline & $\mathrm{N}$ & $\%$ & $\mathrm{~N}$ & $\%$ & $\mathrm{~N}$ & $\%$ & \\
\hline Recurrence at 1 year & 4 & 10.0 & 0 & 0.0 & 9 & 22.0 & 0.004 \\
\hline Recurrent bleeding & 5 & 12.5 & 6 & 15 & 13 & 31.7 & 0.062 \\
\hline Recurrent prolapse & 6 & 15 & 2 & 5 & 7 & 17.1 & 0.215 \\
\hline Completely symptom-free & 29 & 72.5 & 33 & 82.5 & 24 & 58.5 & 0.057 \\
\hline Mean postoperative pain intensity at rest, VAS (mean, standard deviation) & \multicolumn{2}{|l|}{3.1} & \multicolumn{2}{|l|}{5.0} & \multicolumn{2}{|l|}{2.7} & $<0.001$ \\
\hline $\begin{array}{l}\text { Mean postoperative pain intensity during defecation, } \\
\text { VAS (mean, standard deviation) }\end{array}$ & \multicolumn{2}{|l|}{3.8} & \multicolumn{2}{|l|}{6.4} & \multicolumn{2}{|l|}{4.0} & $<0.001$ \\
\hline Analgesic medication use (days, interquartile range) & \multicolumn{2}{|c|}{$5(3-7)$} & \multicolumn{2}{|c|}{$8(6-11)$} & \multicolumn{2}{|c|}{$5(2-7)$} & $<0.001$ \\
\hline Time to return to regular activity or work, days (interquartile range) & \multicolumn{2}{|c|}{$15(5-14)$} & \multicolumn{2}{|c|}{$30(14-35)$} & \multicolumn{2}{|c|}{$24(9-30)$} & $<0.001$ \\
\hline Wexner score & \multicolumn{2}{|c|}{$3(0-5)$} & \multicolumn{2}{|c|}{$3(0-5)$} & \multicolumn{2}{|c|}{$2(0-2)$} & 0.125 \\
\hline Patient's subjective evaluation of operation 0-10 VAS (interquartile range) & \multicolumn{2}{|c|}{$10(10-10)$} & \multicolumn{2}{|c|}{$9(8-10)$} & \multicolumn{2}{|c|}{$9(9-10)$} & 0.002 \\
\hline \multicolumn{8}{|l|}{ Quality of life (SF-36), mean (interquartile range) } \\
\hline Physical functioning & \multicolumn{2}{|c|}{$89(93-100)$} & \multicolumn{2}{|c|}{$89(85-100)$} & \multicolumn{2}{|c|}{$92(95-100)$} & 0.976 \\
\hline Role functioning/physical & \multicolumn{2}{|c|}{$84(100-100)$} & \multicolumn{2}{|c|}{$90(100-100)$} & \multicolumn{2}{|c|}{$87(100-100)$} & 0.735 \\
\hline Role functioning/emotional & \multicolumn{2}{|c|}{$83(100-100)$} & \multicolumn{2}{|c|}{$84(67-100)$} & $90(1$ & $-100)$ & 0.289 \\
\hline Energy/fatigue & 49( & & $46(4$ & 50) & $45(4$ & & 0.462 \\
\hline Emotional well-being & 57( & & $53(4$ & 60) & $49(4$ & & 0.475 \\
\hline Social functioning & 42( & & $41(4$ & 55) & $50(4$ & & 0.859 \\
\hline General health & 60( & & $58(5$ & & $53(4$ & & 0.023 \\
\hline Health change & 86( & 100) & $83(7$ & 100) & $82(7$ & $00)$ & 0.392 \\
\hline FIQOL, mean (interquartile range) & & & & & & & \\
\hline Lifestyle & $4(4$ & & $4(4$ & & $4(4$ & & 0.652 \\
\hline Coping/behavior & $4(4$ & & $4(4$ & & $4(4$ & & 0.759 \\
\hline Depression/self-perception & $4(4$ & & $4(4$ & & $4(4$ & & 0.587 \\
\hline Embarrassment & $4(3$ & & $4(4$ & & $4(4-$ & & 0.144 \\
\hline
\end{tabular}

\section{Outcomes}

The primary outcome of the study was the recurrence of rectal bleeding and prolapse at 1 year after the operation requiring any kind of medical attention or treatment (visit to the doctor or pharmacy, medical, invasive, or surgical treatment).

Secondary outcomes of the study were time to return to work or regular activity, intensity, and duration of perianal pain after the operation (in days), Wexner fecal incontinence score at 1-year visit, QOL based on SF-36 questionnaire and FIQOL at 1 year, and evaluation of the operation by the patient on visual analog scale from 1 to 10 at 1 -year visit.

No change in outcomes or outcome evaluation was allowed after the commencement of the study.

\section{Statistical methods}

The sample size required for the study was calculated using the flexible statistical power analysis program for the social, behavioral, and biomedical sciences, G*Power V 3.1.9.2.
A sample size of 40 patients in each randomized group provides $84 \%$ power to detect an effect size of 0.30 in the recurrence of symptoms at 1 year across the randomized groups, with an alpha of 0.05 .

We used Shapiro-Wilk and Kolmogorov-Smirnov (K-S) tests for the verification of the normality of variables. A statistically significant relationship between the related variables was determined using a number of criteria. For the variables that satisfied the condition of normality, we used parametric ANOVA criteria, which is also called the Fisher analysis of variance, and it is the extension of the $t$ and $z$ tests. For the variables that did not satisfy the condition of normality, we used nonparametric criteria based on the $\chi^{2}$ criterion for the interval and categorical variables, i.e., the Kruskal-Wallis test, which is the nonparametric test equivalent to the one-way ANOVA, and an extension of the MannWhitney $U$ test to allow the comparison of more than two independent groups (in our case, we have three independent patient groups divided by the type of surgery). When the data were described in a four-digit $(2 \times 2)$ frequency tables and when at least one expected value was less than 5, Fisher's exact test 
Fig. 3 Pain scores within the first week of operation

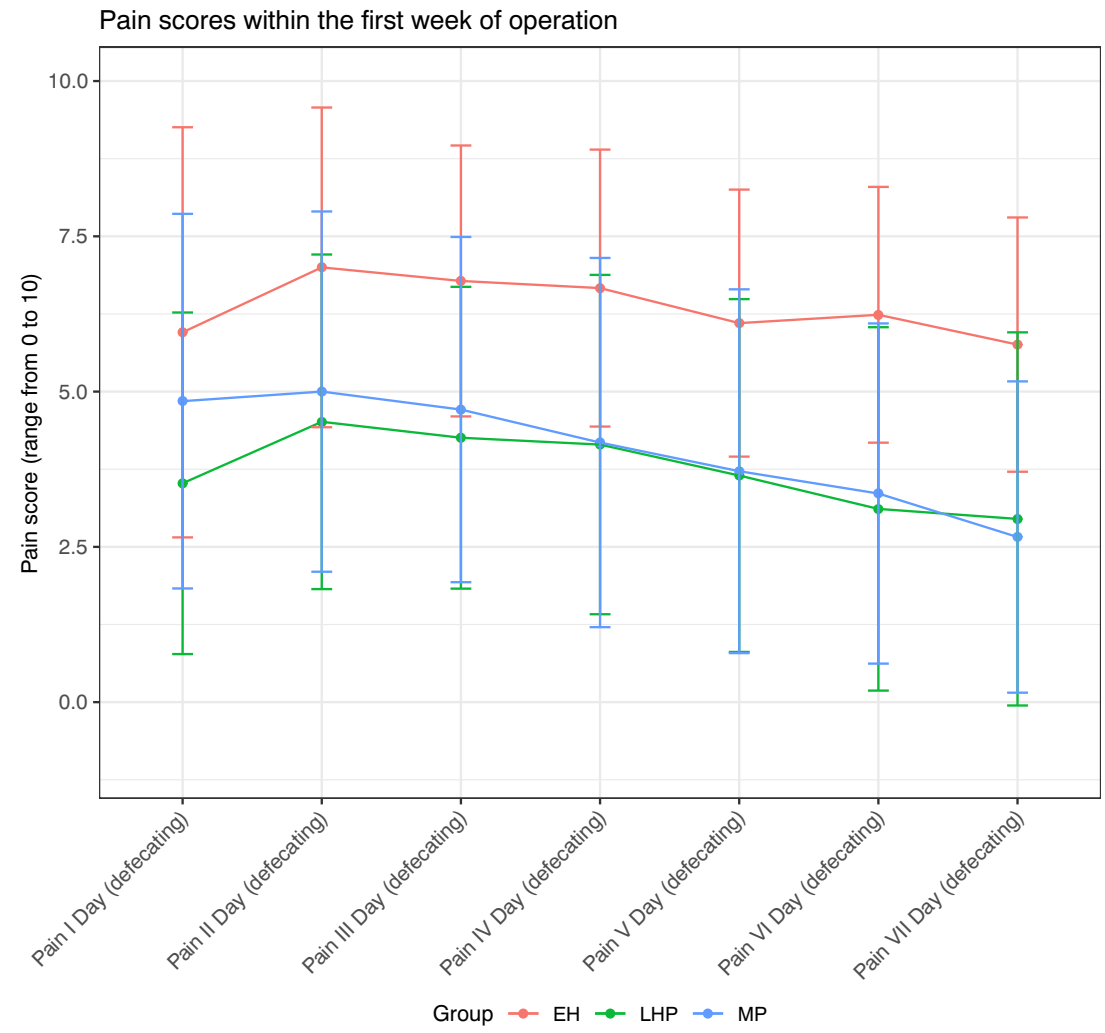

was additionally calculated. We used the Pearson chi-squared criterion to compare two independent groups. We used the Wilcoxon test to compare two dependent groups. We used the marginal homogeneity test to compare the categorical data. We used Student's $t$ test to compare the data that satisfied the condition of normality. The degree of linear dependencies of variables (correlation coefficients) of the Spearman or Kendall $\tau-b$ was calculated for interval variables, when the normality was not satisfied and for the rank variables.

The dependency between variables can be considered statistically insignificant when the two-sided $p$ value (exact sig. (2sided), approx sig.) of all criteria in this category is higher or equal than the established significance level of $0.05(p \geq 0.05)$ and statistically significant when $p<0.05$. The confidence interval (CI) was calculated for a $95 \%$ confidence level.

Statistical analysis was performed using software packages, i.e., R statistical software package V 3.5.3 (2019-03-11) (CThe R Foundation for Statistical computing), R studio V 1.1.463-C 2009-2018 R studio Inc., IBM SPSS Statistics V.23.

\section{Results}

One hundred and twenty-one patients were included in the study, 40 into the LHP group, 40 into the EH group, and 41 into the MP group from April 2016 to April 2017. One-year follow-up was completed in April 2018. All included patients participated in the scheduled visits and completed the followup as required per protocol (Fig. 1).

Baseline demographic and clinical characteristics of the included patients are presented in Table 1. There were no statistically significant differences in demographic and clinical characteristics between the groups at the start of the study.

The operation took $15 \mathrm{~min}$ (10-20) in the LHP group, $29 \mathrm{~min}$ $(20-38)$ in the EH group, and 16 min (15-20) in the MP group (Fig. 2), $p<0.001$.

No significant adverse events occurred after operations. There were no cases of wound infection in our study. No strictures developed in any patients within the duration of the follow-up.

The outcomes of the study are presented in Table 2. The primary outcome - the recurrence of the symptoms of hemorrhoids requiring any kind of treatment — was the best in the $\mathrm{EH}$ group, with no patients $(0 \%)$ having to seek medical attention or treatment for perianal symptoms within 1 year. This was better than in the LHP group (10\%), and MP group (22\%), $p<0.004$. Recurrence of bleeding was observed in $15 \%$ in $\mathrm{EH}$ group, $12.5 \%$ in the LHP group, and $31.7 \%$ in the MP group, $p=$ 0.062 . Recurrent prolapse occurred in $5 \%$ after $\mathrm{EH}$ group, $15 \%$ in LHP group, and $17.1 \%$ in MP group, $p=0.215$. There were $85.2 \%$ completely symptom-free patients after EH, $72.5 \%$ after LHP, and $58.5 \%$ after MP, $p=0.057$.

A comparison of postoperative pain intensity during the first week is presented in Fig. 3. LHP and MP resulted in lower postoperative pain at rest and on defecation than after 


\section{Postoperative use of analgetic medications}

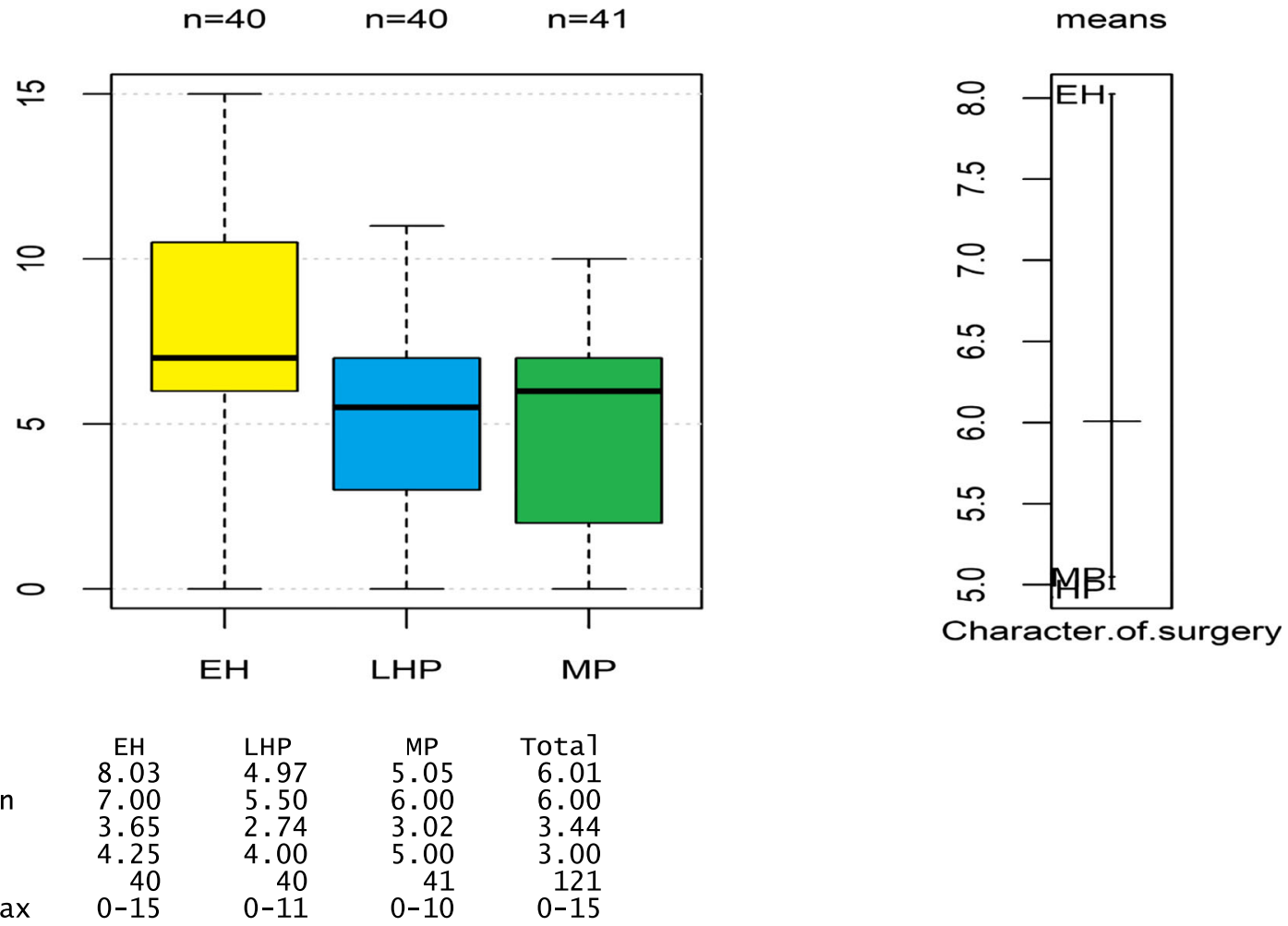

Kruska1-wallis chi-squared $=17.075, \mathrm{df}=2, \mathrm{p}$-value $=0.000196<0.05$. The statistically significant relationship between the type of surgery and the change of health exist.

Fig. 4 Postoperative use of analgetic medications

EH. Patients after LHP and MP used analgesic medications for fewer days than after EH, $p<0.001$ (Fig. 4). Patients after LHP returned to work or regular activity twice faster than after $\mathrm{EH}$ and faster than after MP, $p<0.001$ (Fig. 5).

Results of the QOL of patients are presented in Table 2. General health evaluation of the SF-36 score was better in the EH group 60 (25-100) than in LHP 50 (20-80) or MP 50 (25100 ) groups, $p=0.023$.

The severity of symptoms of fecal incontinence on the Jorge-Wexner score was reduced 1 year after surgery in all the groups, and there were no differences in self-evaluation of incontinence between the groups of patients.

Evaluation of operation by the patients after 1 year is presented in Fig. 5. LHP was evaluated by the patients as the best operation.

\section{Discussion}

Each of the techniques improved the patient's condition, however with different rates of success and side effects. The study found that the most effective of the three techniques was EH, which resulted in the least number of recurrent symptoms of prolapse and bleeding and in no cases of recurrent symptoms requiring treatment, which was the primary outcome of the trial. It was also associated with the best overall QOL as measured by SF-36. MP was the least effective treatment, with the largest percentage of recurrent bleeding, prolapse, and the largest percentage of patients, requiring treatment. LHP was better than MP in terms of recurrence, requiring treatment, recurrent bleeding, and the percentage of completely symptom-free patients.

LHP and MP resulted in significantly shorter duration and lesser intensity of pain than EH. Return to work after LHP was almost twice faster than after EH and significantly faster than MP.

Despite reduced effectiveness, LHP resulted in significantly better patient evaluation on the 10-point visual analog scale than EH or MP.

Significant effort was put to avoid bias within the trial-it was investigator, patient, and evaluator blinded, with computer-generated randomization sequence and complete follow-up. The technique of operation and evaluation of results were mastered and agreed upon among the study researchers before the trial. 


\section{Evaluation of operation by the patient after 1 year}
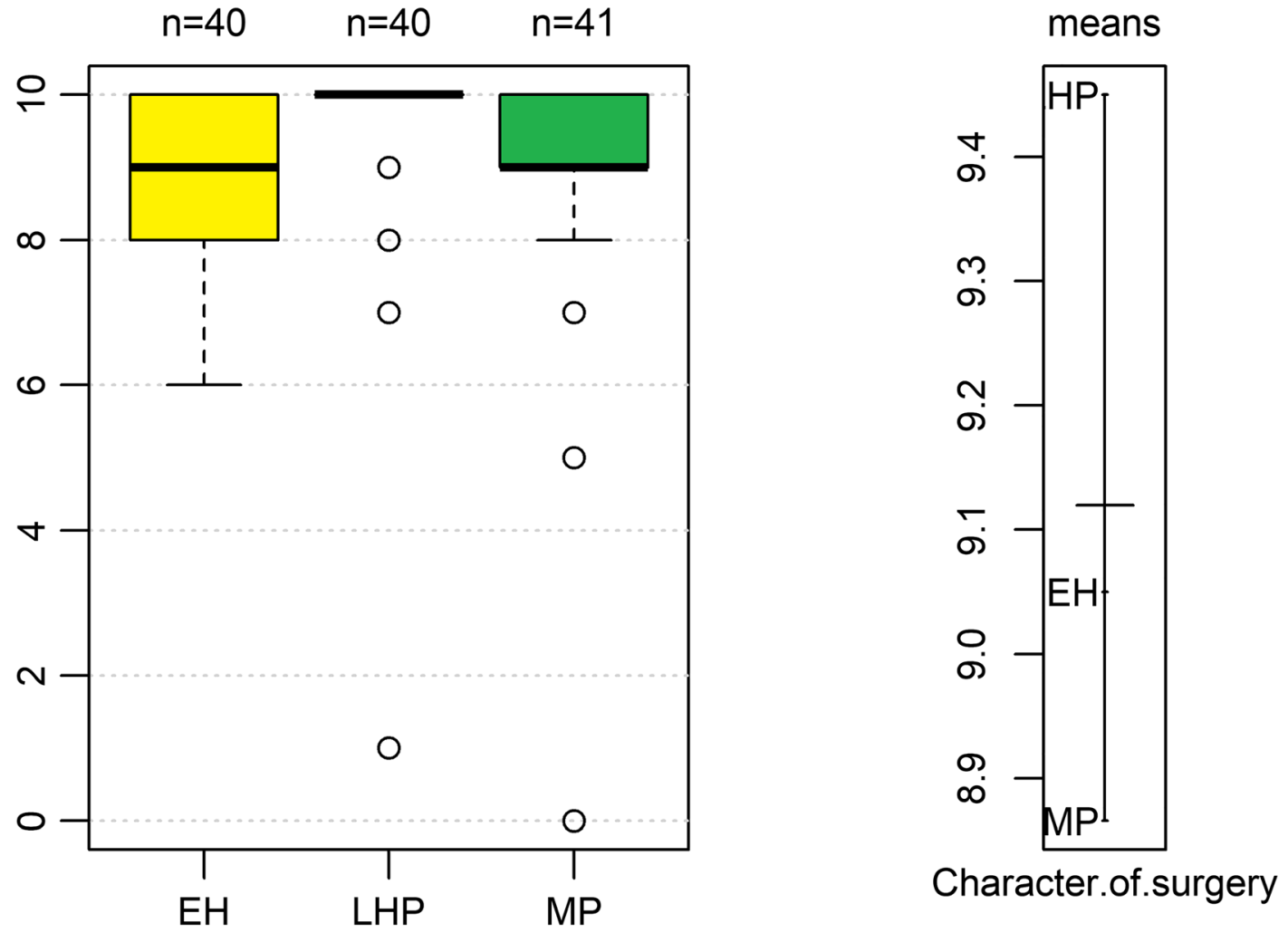

Fig. 5 Evaluation of the operations by the patients

However, this is a single-center trial, and as such, it has limitations when translated to wider populations of patients, surgeons, and institutions. It has to be validated more widely and within larger patient cohorts to confirm the findings.

Measuring outcomes in trials for the hemorrhoidal disease is difficult, and validated symptom scoresSodergren score [13] and Hemorrhoidal Disease Symptom Score and Short Health ScaleHD [14]—were developed to help in this regard. Unfortunately, our study was planned before their publication.

Our study included only the patients with highly symptomatic grade 2 and 3 hemorrhoids, who were considering hemorrhoidectomy and were not deemed suitable for less invasive treatment, such as rubber band ligation. Patients with grade 4 prolapse were excluded from the study, as, based on our experience, LHP is not a suitable technique for grade 4 prolapse.

The interesting finding is the evaluation of the technique by patients on a visual analog scale. Not the most effective treatment was the best according to this measure, and it may probably be expected. In a non-malignant and not life-threatening situation, the choice of treatment and the evaluation of the treatment is most likely based on combined outcome of effectiveness and invasiveness of the procedure, the more effective treatment method and the less morbidity it carries with it, the better the treatment will be. Very effective treatment of circumferential hemorrhoidectomy (Whitehead) is almost never used because of its significant postoperative morbidity.

It is important to note that laser hemorrhoidoplasty is a more expensive technique than the other two, requiring the use of disposable fiber and laser generator, but the cost of the procedure may be reduced by the reduced duration of the operation. However, costs were not evaluated within the study.

There is an inherent risk of bias within the trial because of industry support. This was a university-initiated, but an industry-sponsored trial, where a company (Biolitec) provided laser generator for the duration of the trial and 40 laser kits with an overall price of approximately 10,000 euros. The sponsoring company, however, did not participate in any other way in the design, performance, or analysis of the trial.

There is still no agreed protocol of LHP operation, as different surgeons use different amounts of energy (less vs more than $500 \mathrm{~J}$ ), different locations (symptomatic hemorrhoids vs circumferential coagulation), and different fiber entry points (skin vs hemorrhoid). We have earlier reported on our technique [6], and we think that the technique described above produces the best outcomes in LHP. This, however, remains to be validated by other authors. In conclusion, we found that laser hemorrhoidoplasty is a safe, 
minimally invasive option for hemorrhoids, more effective than MP, and less effective than EH. Patients evaluate this technique better than the other two.

Acknowledgments Biolitec (C) company (Germany) and Mr. Endrik Groehoff provided laser equipment for laser hemorrhoidoplasty procedures without pay. The company had no input or influence in the study design, data collection, analysis, or conclusions.

\section{Compliance with ethical standards}

Conflict of interest The authors declare that they have no conflict of interest.

Study support and financial relationship The study was initiated and run by Faculty of Medicine, Vilnius University, Vilnius, Lithuania, and is a part of a Ph.D. research project of Dr. Donatas Danys.

\section{Appendix}

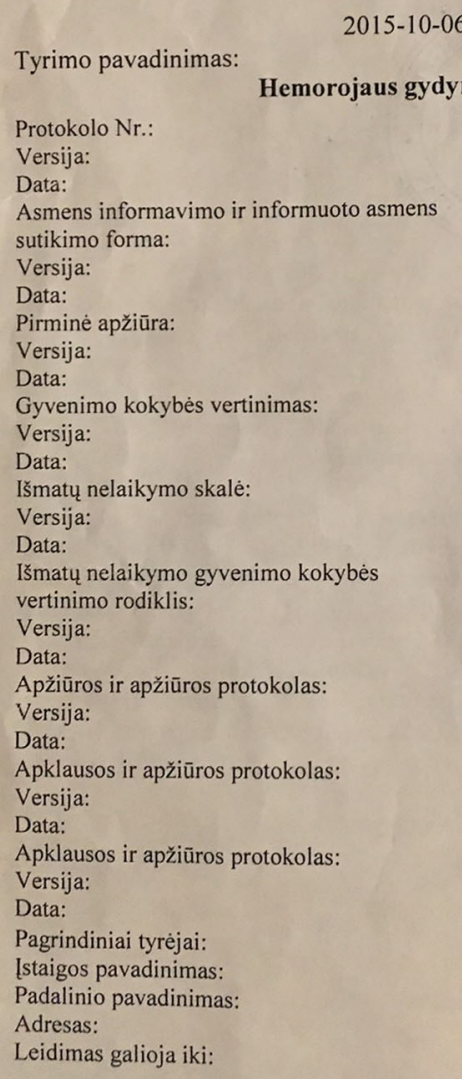

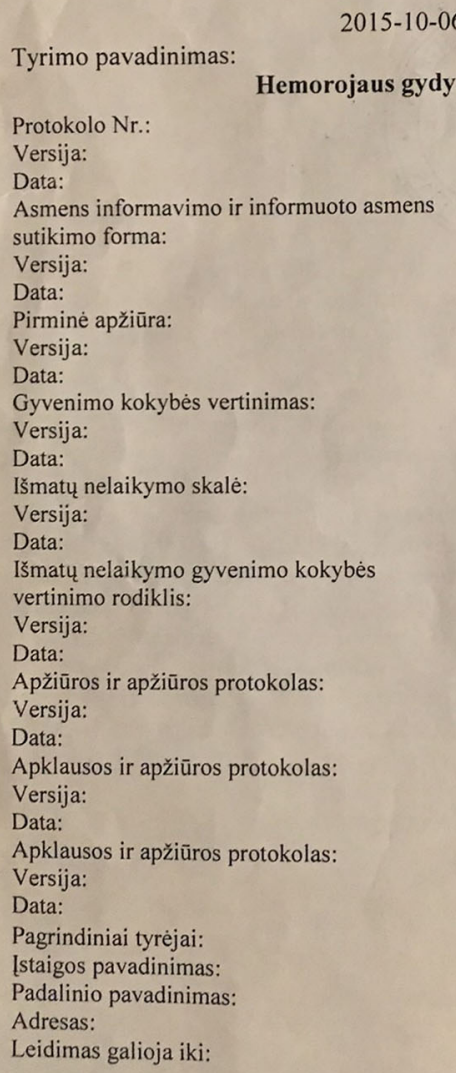

VILNIAUS UNIVERSITETO MED

VILNIAUS UNIVER Vilnius, tel. (8 5) 2687001 , faks. (8 5) 272 8646, el. p. infor@cr.vu.lt. Viešoji istaiga, Universiteto g. 3, LT- O1513 Vilnius, tel. (8 5) 268 7001, fakte, kodas 211950810. Duomenys kaupiami ir saugomi Jurids Fakulteto duomenys: M.K. Ciurlionio g. 21/27, LT-03101 Vilnius, tel. (8 5)
el. p. mf@mf.vu.lt

TYRIMU ETIKOS KOMITETAS

M.K. Ciurlionio g. 21/27, LT-03101 Vilnius, tel. (8 5) 268 6998, el. p. rbtek@mf.vu.It

\section{LEIDIMAS}

\section{ATLIKTI BIOMEDICININI TYRIMA}

2015-10-06

(pildo gydytojas)

2015-06-10

2

2015-06-10

2015-06-10

2015-06-10

1 savaitè po operacijos

2015-06-10

VI savaités po operacijos

2015-06-10

1 metai po operacijos

2015-06-10

Tomas Poškus

Všl Vilniaus universiteto ligoninės Santariškių klinikos;

Pilvo chirurgijos centras;

Santariškių g, 2, Vilnius;

2017-07-01 
Open Access This article is licensed under a Creative Commons Attribution 4.0 International License, which permits use, sharing, adaptation, distribution and reproduction in any medium or format, as long as you give appropriate credit to the original author(s) and the source, provide a link to the Creative Commons licence, and indicate if changes were made. The images or other third party material in this article are included in the article's Creative Commons licence, unless indicated otherwise in a credit line to the material. If material is not included in the article's Creative Commons licence and your intended use is not permitted by statutory regulation or exceeds the permitted use, you will need to obtain permission directly from the copyright holder. To view a copy of this licence, visit http://creativecommons.org/licenses/by/4.0/.

\section{References}

1. Simillis C, Thoukididou SN, Slesser AAP, Rasheed S, Tan E, Tekkis PP (2015) Systematic review and network meta-analysis comparing clinical outcomes and effectiveness of surgical treatments for haemorrhoids. BJS 102:1603-1618

2. Watson AJ, Cook J, Hudson J, Kilonzo M, Wood J, Bruhn H, Brown S, Buckley B, Curran F, Jayne D, Loudon M, Rajagopal R, McDonald A, Norrie J (2017) A pragmatic multicentre randomised controlled trial comparing stapled haemorrhoidopexy with traditional excisional surgery for haemorrhoidal disease: the eTHoS study. Health Technol Assess 21(70):1-224

3. Brown S, Tiernan J, Biggs K, Hind D, Shephard N, Bradburn M, Wailoo A, Alshreef A, Swaby L, Watson A, Radley S, Jones O, Skaife P, Agarwal A, Giordano P, Lamah M, Cartmell M, Davies J, Faiz O, Nugent K, Clarke A, MacDonald A, Conaghan P, Ziprin P, Makhija R (2016) The HubBLe trial: haemorrhoidal artery ligation (HAL) versus rubber band ligation (RBL) for symptomatic secondand third-degree haemorrhoids: a multicentre randomised controlled trial and health-economic evaluation. Health Technol Assess 20(88): 1-150

4. Plapler H, Hage R, Duarte J, Lopes N, Masson I, Cazarini C, Fukuda T (2009 Oct) A new method for hemorrhoid surgery: intrahemorrhoidal diode laser, does it work? Photomed Laser Surg 27(5):819-823. https://doi.org/10.1089/pho.2008.2368

5. Karahaliloglu A (2010) Laser hemorrhoidoplasty- a new surgical procedure for the treatment of advanced hemorrhoidal illness. Coloproctology 32:116-123
6. Danys D, Mazrimas P, Grisin E, Zaks N, Mikalauskas S, Narmontas D et al (2017) Early and one-year results of laser hemorrhoidoplasty for symptomatic hemorrhoids. DisColonRectum 60(6):E241-E241

7. Weyand G, Theis CS, Fofana AN, Rüdiger F, Gehrke T (2017) Laserhemorrhoidoplasty with $1470 \mathrm{~nm}$ diode laser in the treatment of second to fourth degree hemorrhoidal disease - a cohort study with 497 patients. Zentralbl Chir. https://doi.org/10.1055/s-0043120449

8. Schuurman JP, Borel Rinkes IH, Go PM (2012) Hemorrhoidal artery ligation procedure with or without Doppler transducer in grade II and III hemorrhoidal disease: a blinded randomized clinical trial. Ann Surg 255(5):840-845

9. Aigner F, Kronberger I, Oberwalder M, Loizides A, Ulmer H, Gruber L, Pratschke J, Peer S, Gruber H (2016) Doppler-guided haemorrhoidal artery ligation with suture mucopexy compared with suture mucopexy alone for the treatment of grade III haemorrhoids: a prospective randomized controlled trial. Color Dis 18(7):710-716

10. Gupta PJ, Kalaskar S, Taori S, Heda PS (2011) Doppler-guided hemorrhoidal artery ligation does not offer any advantage over suture ligation of grade 3 symptomatic hemorrhoids. Tech Coloproctol 15(4):439-444

11. Jorge JM, Wexner SD (1993) Etiology and management of fecal incontinence. Dis Colon Rectum 36:77-97

12. Rockwood TH, Church JM, Fleshman JW (2000) Fecal incontinence quality of life scale: quality of life instrument for patients with fecal incontinence. Dis Colon Rectum 43:9-17

13. Pucher PH, Qurashi M, Howell AM, Faiz O, Ziprin P, Darzi A, Sodergren MH (2015) Development and validation of a symptom-based severity score for haemorrhoidal disease: the Sodergren score. Color Dis 17(7):612-618. https://doi.org/10. 1111/codi.12903

14. Rørvik HD, Styr K, Ilum L, McKinstry GL, Dragesund T, Campos AH, Brandstrup B, Olaison G (2019) Hemorrhoidal Disease Symptom Score and Short Health ScaleHD: new tools to evaluate symptoms and health-related quality of life in hemorrhoidal disease. Dis Colon Rectum 62(3):333-342. https://doi.org/10.1097/DCR. 0000000000001234

Publisher's note Springer Nature remains neutral with regard to jurisdictional claims in published maps and institutional affiliations. 